\title{
Survey of Failure Modes from 122 Residential Solar Water Heaters
}

ESG, Inc.

Atlanta, Georgia

October 1984

Prepared under Subcontract No. HK-3-03128-1

SERI Technical Monitor: Charles Kutscher

Solar Energy Research Institute

A Division of Midwest Research Institute

1617 Cole Boulevard

Golden, Colorado 80401

Prepared for the

U.S. Department of Energy

Contract No. DE-AC02-83CH10093 


\section{FOREWORD}

This report was prepared under the overall sponsorship of the Office of Solar Heat Technologies of the U. S. Department of Energy. We would like to acknowledge the excellent cooperation of the individual homeowners and the many industry dealers who participated in the effort which also involved a field monitoring program conducted over an extended period of time. At ESG, Inc., special recognition is due William M. Jones, S. M. Blanchard, and the entire Data Analysis staff. At SERI, Charles F. Kutscher provided program guidance for the effort.

$E S G$, Inc. 1984

Approved for

Solar Energy Research Institute

Sohn P. Thornton, Manager
Thermai Systems and Engineering Branch

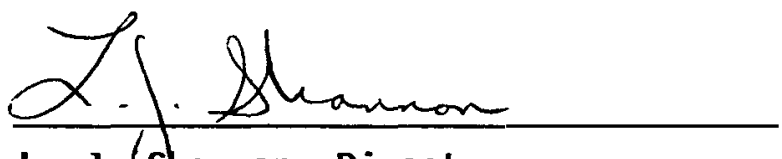

L. J. Shannon, Director

Solar Heat Research Division 


\section{INTRODUCTION}

The Department of Energy's national solar Active Heating and Cooling (AHAC) Program funds research to develop a technical base for the private sector to develop affordable, reliable solar technologies to replace non-renewable energy resources. The Systems Effectiveness Research (SER) program is a subelement of the overall AHAC Program that is specifically concerned with the reliability and operational perfomance of AHAC systems, components, and materials. As part of the SER program, SERI funded ESG, Inc., to study reliability problems in their residential domestic hot water field test program.

This report contains the results of a detailed survey of operating systems aimed at determining which specific reliability problems occurred and their frequency of occurrence. To gather this information, questionnaires were sent to both homeowners and installers covering 122 systems. Results were categorized according to problem severity, location, system type, length of system operation, and time of the year.

This study indicated that approximately $47 \%$ of the systems had at least one reliability problem over a two-year period. Flat-plate collector and storage systems were found to be highly reliable, and most causes of improper system operation could be traced to installation problems. Draindown systems were the least reliable system type largely because of the failure of draindown valves, while drainback designs had the greatest reliability. Differential controllers were responsible for the largest number of failures that resulted in a repair cost in excess of $\$ 50$ to the homeowner.

This report was reviewed by C. Kutscher, R. Farrington, G. Jorgensen, and W. Short, all of SERI. 
Page

I. BACKGROUND AND OBJECTIVES $\ldots \ldots \ldots \ldots \ldots \ldots \ldots \ldots \ldots \ldots \ldots \ldots \ldots \ldots \ldots$

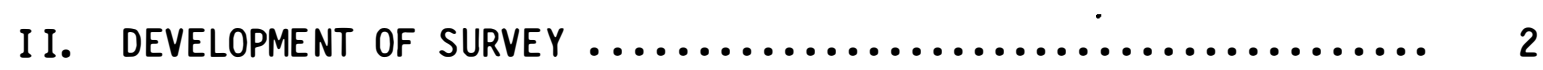

- Homeowner Survey Forms Package....................... 2

- Installer Survey Forms Package....................... 3

- Survey Responses.............................. 4

III. CATEGORIES FOR DATA REDUCTION AND ANALYSIS............. 6

- Initial Discussion............................. 6

- Categories of System Problem Areas................... 6

IV. EFFECTS OF PROBLEMS ON HOMEOWNER.................... 10

V. REPORTED CAUSES OF SYSTEM PROBLEM AREAS............... ו

- Initial Discussion................................. ו ו

- Installation Related Problems........................ 11

- Controller Related Problems........................... 13

- Sensor Related Problems............................. 13

VI. OPERATIONAL TIME WHEN PROBLEMS OCC JRRED................ 14

- System Operational Periods.......................... 14

- Seasonal Variations................................ 15

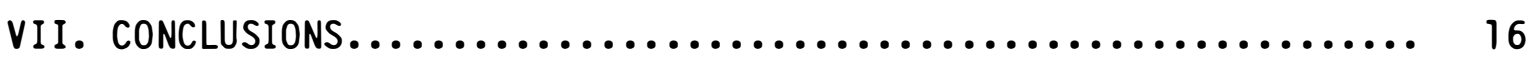

APPENDIX A - PROGRAM PARTICIPANTS SURVEY FORMS PACKAGE..........

- Homeowner Survey Forms Package..................... A-2

- Installer Survey Forms Package.................... A-9

APPENDIX B - INSTALLER FIELD EXPERIENCES SURVEY RESULTS.......... B- 
I. BACKGROUND AND OBJECTIVES

In mid 1981, the U. S. Department of Energy began a program for monitoring the performance of a number of residential solar hot water systems in the southeastern United States. This program was initiated through the Southern Solar Energy Center and later continued by ESG, Inc. During this effort performance data were collected on over 160 systems with emphasis on answering basic questions concerning the overall efficiency and cost effectiveness of the sys tems.

However, it became obvious that a considerable body of information was also available concerning the reliability and maintainability (R\&M) of these systems. This resulted not only because of the direct data collection process which involved the homeowners, but because of the very substantial involvement of the industry installers who participated in the program. Thus, a supplemental effort was conducted with sponsorship through the Solar Energy Research Institute of the U.S. Department of Energy to collect and analyze the data related to R\&M. This covered direct survey of the participants and industry members involved in the performance monitoring program. The survey and the resulting data are presented herein.

The overall objective of the survey was to gather detailed information concerning system operational reliability and maintainability. Information concerning failure modes, operational problems, installer experiences, user comments, etc. was accumulated for analysis purposes.

The major objectives of the survey were as follows:

1) To determine the major areas where system problem areas occurred during the monitoring period.

2) To determine the degree that prevalent problem areas differ for specific system types, components, geographic locations, etc. 
3) To gather sufficient and detailed information on system R\&M problem areas so as to categorize identified problem areas with a high level of confidence.

4) To gather secondary information, related to homeowner and installer experience, etc., from the program participants.

\section{DEVELOPMENT OF SURVEY}

ESG placed a considerable amount of importance on the development of an effective means for gathering the R\&M data from the field test systems. It was considered imperative to develop a survey format which would gather factual information concerning failure modes while not appearing overwhelming to participants in the magnitude of requested information.

Two groups of program participants were surveyed. The groups were the installer participants and the homeowner participants. Specialized surveys were developed and distributed by mail to each group. The survey forms were primarily designed to identify and gather data on problems which occurred during the performance monitoring periods. As mentioned, secondary data were also gathered on use patterns of the homeowners and the overall R\&M experiences of the installers.

Homeowner Survey Forms Package

The homeowner survey package was distributed to 143 homeowners. The total survey package is found in Appendix A. As shown, the survey package had two parts, Data Form $A$ and Data Form B.

Form A was totally concerned with identifying and gathering detailed information on system failure modes and other R\&M problems. The major areas addressed by Form $A$ were the following:

1) What were the system problems?

2) How were the problems noticed?

3) What maintenance was performed? 
4) What components were replaced?

5) What were the known causes of the problems?

6 ) What were the costs of problems to the homeowner?

Each homeowner was requested to complete one Data Form $A$ for each problem that was realized by their system. Included in the data package was the homeowner's latest Monthly Summary Report (MSR). The MSR is a performance report which includes a list of problems reported during the field test program. The list was provided to help the homeowner review the events and dates relating to system problems. Of course, the homeowner was asked to include any problems not listed on the MSR.

Data Form B for the homeowner participants was designed to gather general information on the interaction of the homeowners with their solar water heater. This secondary information became useful to the analysis efforts because homeowners could be categorized according to hot water usage profiles and general attitudes toward their system.

Also included with the forms package was a cover letter and an example listing of system R\&M problem areas. The cover letter included information concerning the importance of the survey effort as well as directions to the homeowner for properly completing the forms package. The example listing of system R\&M problem areas aided the homeowner in identifying types of system problems.

\section{Installer Survey Forms Package}

The installer survey forms package also had two parts, Data Form A and Data Form B. Thirty-six installers were distributed the forms package, see Appendix A. The installer's Data Form A was very similiar to the homeowner's Data Form $A$. Installers were requested to complete a Data Form $A$ for each problem encountered by their monitored systems. 
Data Form B was utilized to gather data on the total field experiences of the installers. Included in Data Form B was a listing of system components and related problem areas. The installers were requested to rank the system components and problem areas in the order of frequency of occurrence. This information allowed for comparisons of the problem areas identified at the monitored sites versus overall problem areas from total installer experiences. The second section of Data Form B was designed to gather additional information on failure modes and the time span associated with problem occurrences. Also, installers were requested to provide comments concerning R\&M experiences with specific sys tem components.

Appendix $B$ of this report presents additional results from the installer's survey forms. It is extremely interesting to compare the results from the field test survey with the results from the survey on overall installer field experience. The conclusions derived from the surveys appear similar and one offers verification as to the accuracy of the other.

\section{Survey Responses}

As mentioned, the survey forms were distributed to the two groups of program participants: installers and homeowners. ESG distributed the forms to both participant groups in order to maximize the possibility of receiving at least one response on each monitored site from one or the other group. Table 1 shows the locations of the homeowner participants and the corresponding number of responses and percentage of completed survey forms returned to ESG. Table 1 also shows the installer locations and the corresponding number of responses.

During the system performance monitoring phase of the test program over 160 solar water heaters were instrumented for data collection at on time or another. The number of homeowner participants available during the period the survey was conducted was 143. Some of the major reasons for the reduced number were as follows: 
1) Homeowner moved

2) Homeowner deceased

3) Homeowner's lack of participation

ESG distributed a total of thirty-six survey forms to the installer participants. The response rate of the survey for the installers (33\%) was significantly lower than the homeowner response rate (73\%). Again, the reasons for this situation were varied. However, the two major reasons were:

1) Installer out of business

2) Installer didn't have time to participate

Numerous attempts were made to increase the program participant response rate. These efforts included personal telephone contacts and follow-up letter correspondence. The majority of the initial non-responses were sent the survey forms again.

ESG combined the homeowner and installer responses to identify the total number of system locations where at least one detailed survey form response was received. Table 1 provides information on the number of respondents and their locations. A significant response rate (85\%) was recorded.

It was encouraging to note the level of detail and the amounts of verifiable information gathered during the survey. The level of knowledge displayed by the individual homeowners was particularly noteworthy. Thus, a high level of confidence exists on the validity of the data. By design, there were numerous situations where both the homeowner and installer responded for the same system problem. In an overwhelming majority of these cases, the homeowner and installer responses were identical and identification of the problem area, the cause of the system problem, the required maintenance, and the costs associated for repairs were verified. 
Initial Discussion

The remaining sections of this report are primarily concerned with the presentation of the data and major findings derived from the survey. A majority of the information is presented in tabulation format to allow the reader easy reference. Findings of major importance or significance are addressed in the text.

Categories of System Problem Areas

of the 143 solar water heater sites available for data gathering during the survey, information was gathered on 122 systems or $85 \%$ of total. A breakdown of the system types and locations is given on Table 2. There were a total of 83 solar-related problem areas identified during the survey. These problem areas occurred on 57 of the 122 solar water heater systems which is $47 \%$ of the total sample.

As shown in Table 2, five solar water heater system designs are listed. The system types are categorized in terms associated with freeze protection. "Recirculation" refers to system design types which prevent freeze damage by recirculating heated water from the storage tank through the exposed piping network when freezing conditions exist. "Drainback" are the systems designed to prevent freeze damage by draining the water in the piping network to a reservoir tank whenever the circulating pump is shut off. "Closed Loop" are the system types which have a glycol based antifreeze solution added to the water in the piping network to prevent freezing. The closed loop systems also include systems which utilize silicone oils as the collector-to-storage heat transfer fluid. "Draindown" refers to system types which utilize an automatic draindown valve which is activated during freezing conditions. This valve allows water to drain from exposed piping and discharge from the system by gravity flow. The final system type listed in Table 2 is the manual freeze system type. This design type represents the systems which require "manual" operation of a valve in order to drain water from exposed piping when freezing conditions are anticipated. 
In order to understand the various areas of system operational problems, the survey R\&M data were categorized according to frequency of occurrence. The reported system problem areas were divided into two kinds of problems. Type I problem areas were considered major problem areas and were further defined as: 1) any problem resulting in a major system component replacement such as controllers, pumps, draindown valves, etc., 2) any problem resulting in out-of-pocket money in excess of $\$ 50.00$ for the homeowner, or 3) any problem resulting in freeze damage. The important consideration in separating system problem areas into Type I or Type II was whether a problem area represented a potential for significant cost to the homeowner. Type II problem areas were defined as any "other" reported problems not included as Type I problem areas. Two frequent kinds of Type II problem areas were service calls to repair a leaking fitting and replacement of minor system components such as air vents or $P / T$ valves. There were a total of thirty-two Type I and fifty-one Type II problem areas.

Table 3 displays the breakdown of these problem areas. A very important item given in Table 3 is the row labeled "number of problems per reporting system." These values are calculated by dividing the number of reported problem areas for a given system design type by the rumber of reporting systems for the same type. For instance, the recirculation type system designs reported a total of twenty-seven system problem areas. From Table 2, the total number of reporting recirculation systems is forty-six. Therefore, the total number of problems per reporting system for recirculation type system is .59. Table 3 shows this further divided into Type I and Type II problems $(.20+.39)$. As noted, the recirculation systems experienced nine Type I problem areas and eighteen Type II problems which equals twenty-seven total problem areas. The draindown systems have a total value of $1.50(.83+.67)$ which is relatively high in comparison to other system types. (NOTE: Because of the relatively large number of problem areas with draindown systems, data in the remaining sections of this report is sometimes presented with the draindown systems separated from the total population.) 
Referring to Table 3, installation related problems represented the category with the most frequent occurrences. Thirty-six percent of all reported problems were in this category. Installation related problems included not only the actual workmanship at the installation but also problems associated with material and component specification and system design. It is believed that a majority of the reported system problems could have been totally avoided if the system install er and/or designer had been more "careful" with system installation or better informed on material properties and proper applications.

For example, one installer utilized a polybutylene piping system on the collector supply and return lines for all five of his monitored systems. The piping was not properly supported and higher than normal operational temperatures caused the piping to deform at the unsupported sections. This resulted in water remaining in the collector piping network during freezing conditions. One-by-one the piping systems failed and were replaced. One could conclude that plastic pipe should not be specified where potentially high temperatures are likely, such as on the collector piping system. This problem was without question, an installation related problem because the material specified probably should not have been installed.

The next single most frequent problem area was concerned with the differential temperature controllers. One of the major reported causes of controller failures was due to lightning. Many of the controllers utilized had no internal circuit protection against high surges caused by a nearby lightning strike. (ESG is only reporting the cause of the failure indictated in the survey forms by the participants. It could very well be true that controller failures are only believed to be caused by electrical storms. In any case, it is obvious that all controllers should be protected from external power surges.)

Draindown systems were plagued with a greater than average number of system problems. The draindown valves utilized with these system types caused a wide assortment of operational problems. The valve failures were 
prevalent to the degree that this problem area warranted a separate system problem category. Field responses from installers indicate that there is little confidence in the continuous, trouble-free operation of this valve. As indicated in the survey data gathered, draindown problem systems were $33 \%$ of the total number of problem systems while only $15 \%$ of the total number of reporting systems.

Referring again to Table 3, another problem category with a significant number of occurrences was the category labeled "other." This category was designated to include problem areas of either lower frequency of occurrence or problem areas considered to be lower in importance. The following is a listing of the types of problem areas included in the "other" category.

1. Pressure/temperature valve leaking

2. Check valve faulty

3. Air vent malfunctioning

4. Valve seal leaking

5. Glycol added

6. Leak at sight glass

7. Drainback reservoir tank leaking

The problem category in Table 3 listed as "corrosion" refers to problems which developed due to sediment buildup in tanks or in the piping network. Corrosion was the only problem area which was determined to be geographically exclusive. All of the corrosion related problems were experienced by systems located in the Jacksonville, Florida area.

"Glazing" refers to problems related to the glass or plastic covers for the collector panels. There were three instances of glazing problems. Two of these were due to the fading of the polyester fiberglass material utilized as glazing. There was only one instance of glass breakage out of an approximate total of over 200 collectors operating for an average of 2.5 years. 
IV. EFFECTS OF PROBLEMS ON HOMEOWNER

One of the most one-sided responses from the homeowner survey was concerned with attitude. ESG asked the individual homeowners whether or not they were "glad" they purchased a solar water heater. An overwhelming 92\% of the homeowners responded "yes" with the major reason being "dollar savings." The second most recorded reason for liking their solar water heater purchase was due to the large amounts of hot water available. It was somewhat surprising to discover homeowners with relatively low performing systems remaining pleased with their solar system purchase. In the majority of the "yes" responses, the homeowners were enthusiastic in their expression of positive opinions toward solar energy.

of the 83 system problem areas identified in the survey, twelve resulted in out-of-pocket expenditures for ten homeowners. The average cost per problem to the homeowner was $\$ 105.00$. As it was, all but one of the homeowners remained "glad" they purchased their system. The only homeowner in this group who was dissatisfied with the purchase spent a total of $\$ 674$ in repairs. Without including this particular homeowner, the average cost per reported problem to the homeowner was $\$ 78$.

The ten systems identified above were in operation for an average of 3.3 years. The following is a list of the problem areas which resulted in a cost to the riomeowner.

\begin{tabular}{lrc} 
Problem Area & Average Cost & \# of Occurrences \\
\cline { 2 - 3 } Controller replaced & $\$ 65$ & \\
Pump replaced & 244 & 3 \\
Sensor replaced & 48 & 3 \\
Air vent replaced & 20 & 1 \\
Glazing replaced & 30 & 1 \\
Glycol added & 74 & 1 \\
Pump seals replaced & 99 & 1 \\
Freeze damage repaired & 175 & 1
\end{tabular}




\section{REPORTED CAUSES OF SYSTEM PROBLEM AREAS}

Initial Discussion

In this section of the report the causes of the major problem related categories, listed in previous sections, are addressed. In many cases, there are problems where the "actual" causes of the component failures are unknown. For instance, when a controller failed, the specific cause of the failure may only be determined during an actual physical inspection of the unit. Physical component inspection is beyond the scope of this work effort. Therefore, data is presented as it was received by ESG, and component failure can only be discussed in terms of the frequency of occurrence in most instances.

\section{Installation Related Problems}

of the 83 reported system problems, 30 are related to installation. The installation related problem category includes the areas of actual on-site workmanship, material and equipment specifications, and system design. If a problem is a direct result of inadequacies in any of these areas, it is designated as an installation or installer related problem.

Actual on-site workmanship problems accounted for 16 of the 30 installation related problems. The following is a listing of the reported workmanship problems.

Workmanship Problems

1) Sensor located in wrong place

2) Pipes not properly sloped

3 ) Leaks where pipes enter roof

4) Leak at pipe fittings

5) Collector supply and return piping reversed

6) Solder in pipe
\# of Occurrences 
Material and equipment specifications are of major importance to the troublefree operation of solar water heaters. At times, installers may attempt to "cut corners" and install equipment and utilize materials that are not designed for the application. One major area of improper material specification is roof piping insulation. At this stage of industry development, it is common knowledge that elastomeric insulation systems require protection from ul traviolet degradation. However, four instances were recorded where the pipes were not properly protected and shrinkage and ultimate failure of the insulation system occurred.

Equally apparent in the problem area of material specifications is the misuse of plastics in solar systems. There is without question a number of plastic resin systems which are designed to maintain thermal and mechanical properties for solar system applications. In two separate cases, however, installers selected the wrong application for plastics which resulted in six systems reporting problems. The two cases involved the use of plastic tubing for sight glasses and the second, and much more consequential, was the use of polybutylene piping as the collector supply and return lines. As was previously discussed, polybutylene will not maintain mechanical properties above $230^{\circ} \mathrm{F}$ and should not be utilized where there is a potential for these temperatures.

The last area where material and equipment specifications were inadequate is concerned with pump specifications. Two cases were reported where cast iron bodied circulating pumps were utilized in open or vented systems. These situations resulted in eventual replacement of both pumps, where one pump actually became corroded to the point where it seized up.

The last problem area in the installation related problem category deals with system design. This area seems to be of only minor significance to operational downtimes. Two instances were reported where check valves were omitted from the original system design resulting in an excessive heat loss due to thermosiphoning from the storage tank. These situations could well be considered a workmanship problem area, however, there were indications with one of the systems that this situation was a system design related problem area. 
It is difficult with this type of data collection to identify other system design problems, especially those relating to low system performance efficiencies. As previously mentioned, the field test program was designed to gather performance data and therefore performance histories do exist. However, there would be a need to gather data by site visits on the lower performing systems in order to accurately identify low performers which result from poor system design.

\section{Controller Related Problems}

There were eleven controller failures reported during the survey of the 122 solar water heaters. The actual and specific causes of the failures of differential temperature controllers are unknown. As mentioned, in order to determine actual cause, the controllers would have to have been physically inspected. Since this was not a part of the project's scope of work, it was not done and the reports on the causes must be taken at face value. Undoubtedly, the majority of the failed controllers were returned to the manufacturer for inspection.

Sensor Related Problems

Two of the most frequent means that a homeowner identifies a system problem area are when he/she notices the pump running at night or not running during sunny days. Usually when these symptoms are noticed, the controller or one of the control sensors is at fault. Sensor related problems accounted for $10 \%$ of the total number of reported system problems and all of these problems were detected by one or the other symptom. Every sensor problem reported was remedied by replacement of at least one control sensor.

As with the controller related problems, it is difficult to determine "actual" cause of sensor failure. A sensor failure during freezing conditions can be extremely costly for draindown and recirculation type systems. It is obvious that homeowners should maintain a "watchful eye" on their system in order to quickly detect sensor malfunction. 
VI. OPERAT IONAL TIME WHEN PROBLEMS OCCURRED

System Operational Periods

Information was gathered concerning the time when problems occurred in relation to the installation date. Table 4 and Table 5 show the numbers of problems which occurred over time following the original installation date. The data are accumulated in time blocks of six mcnths duration. This presentation of data permits the comparisons over a time frame up to 30 months, or greater.

The majority of the data were gathered during the first and second year of operation; however, there were a number of systems where R\&M data were gathered during the third, fourth, and greater years of operation.

In order to emphasize the significance of the numerous problems experienced by the draindown type systems, th zse system types were separated from the total population in Table 4. As discussed in an earlier section, the problem areas were also divided into Type I and Type II problems in Table 4 and Table 5.

As shown in Table 4, a number of interesting observations can be made. The important values to note are the values in the rows designated as "the number of problem areas per system" shown in Table 4. These values equate the relative number of problems to the number of systems reporting during the specific periods of system operation. The number of reporting systems decreases greatly after the 24 th month of operation, therefore, data presented after that time is of less significance. The draindown type systems do not have any operational histories after the second year. Figure 1 depicts the data given in Table 4 with the Type I and Type II problems totaled.

Table 4 shows that the recirculation, drainback, closed loop, and manual freeze type systen; appear to experience Type II problem areas during early system operation. These system types also appear to experience an increasing number of Type I problem areas in relation to the 
number of reporting systems during later operational periods. Conversely, the draindown type systems experienced Type I problems in relatively significant numbers during early operational periods. Data is not available for operational periods beyond two years for draindown systems.

Table 5 shows the operational time periods when particular categories of problems occur. The problem categories are divided into two groups. Group $A$ includes the recirculation, drainback, closed loop, and manual freeze system types. Group $B$ includes the draindown systems only. Referring to Table 5, it appears that a majority of these Type II problem areas are concerned with installation related problems and minor system component failures such as $P / T$ valves and air vents. As the system operational time increases beyond two years, Type II problems decrease accordingly and the more serious Type I problems begin to increase in number per reporting system. The majority of controller and pump failures occur after the first year of system operation. The draindown systems experienced failures of the valves early in system life for a specific reason. These draindown valve failures usually occurred during the first winter season, which was usually in the first six months of operation.

\section{Seasonal Variations}

This section of the report is concerned with examining seasonal relationships between system types and problem areas. The 83 reported system problem areas were tabulated by the season of the year in which they occurred. Table 6 and Figure 2 show the seasonal variations in the number of problem areas according to the various system types. Table 6 presents the data by Type I and Type II problems as discussed earlier. Figure 2 shows the combined totals. Table 7 displays the individual problem area categories and the corresponding number of problems on a seasonal basis.

According to Table 6, the drainback and closed loop type systems seem to have their greatest number of problems in the summer season while the recirculation and draindown type system have their greatest number of operational problems in the winter season. It is interesting to note that the spring season displays the fewest number of system problem areas. 
A greater number of the total problem areas occur during the winter season. One reason for this situation is due to the colder and, at times, freezing temperatures experienced by solar water heaters during this season; nine systems recorded freeze damage. Installation related problem areas, such as the piping system installation, most readily became a Type I problem during the winter season due to freeze damage. As shown in Table 7, every problem area had the greatest number of occurrences in the winter season except the sensor related problems. Sensor related problems seemed to be most frequent during summer and spring seasons. Other data show that the higher than normal operating temperatures in the collector subsystems in the summer months appear to cause a higher rate of sensor failures.

VII. CONCLUSIONS

Overall, the survey was considered particularly useful since it provided some of the first data on a reasonable number of state-of-the-art systems over a time period which exceeded 24 months. The data is presented in a manner which may be helpful in determining the areas where continuing industry and government research efforts may be helpful. Some of the key observations which may be made are as follows:

1. Of the 122 solar water heater systems which provided reliability and maintainability data, 57 systems reported at least one problem area. This results in an impressive 65 solar water heater systems which operated without any R\&M problems for a period of approximately two years.

2. The flat plate collector and storage subsystems are highly reliable parts of residential solar water heater systems.

3. Installation related problems are the most frequent cause of improper system operation. In all probability, this type of problem should decrease as existing installers learn from their mistakes and new installers, hopefully, will also benefit from the growing base of experience. 
4. Draindown type solar water heaters installed in the program from mid 1981 to early 1982 experienced a relatively high number of operational problems with failure of the draindown valve as the most prevalent cause. Approximately 9 out of 10 draindown systems appear to have Type I system operational problems.

5. The majority of system problems occur during the winter season.

6. The differential temperature controllers were responsible for the greatest number of Type I problem areas. Nearby lightning strikes appear to be a significant cause of controller failure. Type I problem areas are defined as a problem area: (1) requiring a major system component replacement, (2) resulting in out of pocket money from the homeowner in excess of $\$ 50.00$, or (3) resulting in freeze damage.

7. There is actually only a slight difference in the total number of problems between the first year and second year of system operation when the draindown systems are not included in the test population. Type II problem areas are more frequent during early system operation.

8. The drainback type solar water heater is the least likely system type to have a Type I problem.

9. An overwhelming majority of homeowners are "glad" they purchased a solar water heater even though a number of system problems were experienced. 


\begin{tabular}{|c|c|c|c|c|c|c|c|}
\hline Location & $\begin{array}{c}\begin{array}{c}\text { Queried } \\
\text { Homeowners }\end{array} \\
\end{array}$ & $\begin{array}{l}\text { Responding } \\
\text { Homeowners } \\
\end{array}$ & $\begin{array}{c}\text { Queried } \\
\text { Instailers } \\
\end{array}$ & $\begin{array}{l}\text { Responding } \\
\text { Installers } \\
\end{array}$ & $\begin{array}{c}\# \text { of } \\
\text { Installer } \\
\text { Systems } \\
\end{array}$ & $\begin{array}{c}\text { of } \\
\text { Homeowner or } \\
\text { Installer Systems }\end{array}$ & $q$ Return \\
\hline 1. Florida & 84 & 62 & 20 & 8 & 38 & 72 & $86 \%$ \\
\hline 2. North Carolina & 9 & 7 & 3 & 0 & 0 & 7 & $78 \%$ \\
\hline 3. Virginia & 14 & 6 & 3 & 2 & 9 & 12 & $86 \%$ \\
\hline 4. Georgia & 7 & 6 & 2 & 1 & 4 & 7 & $100 \%$ \\
\hline 5. South Carolina & 5 & 5 & 1 & 0 & 0 & 5 & $100 \%$ \\
\hline 6. Alabama & 14 & 12 & 3 & 1 & 8 & 13 & $93 \%$ \\
\hline 7. Texas & 9 & 5 & 3 & 0 & 0 & 5 & $56 \%$ \\
\hline 8. Kentucky & 1 & 1 & 1 & 0 & 0 & 1 & $100 \%$ \\
\hline TOTALS & 143 & 104 & 36 & 12 & 59 & 122 & $85 \%$ \\
\hline
\end{tabular}

TABLE 1. NUMBER AND LOCATIONS OF RESPONDING PROGRAM PARTICIPANTS 


\begin{tabular}{|l|cccccc|}
\hline \multirow{2}{*}{ STATES } & \multicolumn{5}{|c|}{ SYSTEM TYPES } \\
\cline { 2 - 6 } & Recir. & Draindown & Drainback & $\begin{array}{c}\text { Closed } \\
\text { Loop }\end{array}$ & $\begin{array}{c}\text { Manual } \\
\text { Freeze }\end{array}$ & Totals \\
\hline 1. Florida & 44 & 10 & 13 & 1 & 4 & 72 \\
2. North Carolina & 0 & 0 & 0 & 7 & 0 & 7 \\
3. Virginia & 0 & 3 & 0 & 9 & 0 & 12 \\
4. Georgia & 0 & 2 & 1 & 4 & 0 & 7 \\
5. South Carolina & 2 & 0 & 0 & 3 & 0 & 5 \\
\hline 6. Alabama & 0 & 0 & 9 & 4 & 0 & 13 \\
\hline 7. Texas & 0 & 3 & 1 & 1 & 0 & 5 \\
\hline \hline Totals & 0 & 0 & 0 & 1 & 0 & 122 \\
\hline
\end{tabular}

TABLE 2. LOCATIONS OF REPORTING SYSTEMS ACCORDING TO SYSTEM TYPE 
SYSTEM TYPE

\begin{tabular}{|c|c|c|c|c|c|c|c|c|c|c|c|c|c|}
\hline \multirow[b]{2}{*}{ PROBLEM CATEGORY } & \multicolumn{2}{|c|}{ Recirculation } & \multicolumn{2}{|c|}{ Draindown } & \multicolumn{2}{|c|}{ Drainback } & \multicolumn{2}{|c|}{ Closed Loop } & \multicolumn{2}{|c|}{ Manual Freeze } & \multicolumn{2}{|c|}{ Totals } & \multirow{2}{*}{$\frac{\text { \& of Total }}{I \& I I / T o t a l}$} \\
\hline & 1 & $11^{2}$ & $I$ & III & I & II & I & II & $I$ & II & I & II & \\
\hline Installation & 3 & 4 & 2 & 7 & 1 & 6 & 2 & 5 & & & 8 & 22 & $36 \%$ \\
\hline Controllers & 3 & & 5 & & & & 2 & & 1 & & 11 & & $13 \%$ \\
\hline Pumps & 2 & & 1 & & 1 & & & & & & 4 & & $5 \%$ \\
\hline Sensors & 1 & 3 & & 1 & & & & 3 & & & 1 & 7 & 108 \\
\hline Draindown Valves & N/A & $N / A$ & 7 & & N/A & N/A & $\mathrm{N} / \mathrm{A}$ & $N / A$ & N/A & N/A & 7 & & $8 \%$ \\
\hline Glazing & & 2 & & 1 & & & & & & & & 3 & $4 \%$ \\
\hline Other & & 6 & & 3 & & 4 & 1 & 2 & . & & 1 & 15 & $19 \%$ \\
\hline Total & 9 & 18 & 15 & 12 & 2 & 11 & 5 & 10 & 1 & & 32 & 51 & -- \\
\hline$\%$ of Total & & & & & & & & & & & & & $100 \%$ \\
\hline $\begin{array}{l}\text { \# of Problems } 3 \\
\text { per Reporting } \\
\text { System }\end{array}$ & .20 & .39 & .83 & .67 & .08 & .46 & .17 & .33 & .25 & 0 & .26 & .42 & -- \\
\hline
\end{tabular}

Notes: 1)Denotes Type I problem areas as defined as any problem resulting in any one of the following: (a)replacement of major system component; (b)out of pocket cost to homeowner in excess of $\$ 50$; or (c) freeze damage.

2) Denotes Type II problem areas as defined as any problem not designated as Type I problem. 3) See explanation in text. 
MONTHS OF OPERATION

\begin{tabular}{|c|c|c|c|c|c|c|c|c|c|c|c|c|c|}
\hline \multirow{2}{*}{$\begin{array}{l}\text { SYSTEM } \\
\text { TYPE }\end{array}$} & $0-6$ & \multicolumn{2}{|c|}{$7-12$} & \multicolumn{2}{|c|}{$13-18$} & \multicolumn{2}{|c|}{$19-24$} & \multicolumn{2}{|c|}{$25-30$} & \multicolumn{2}{|c|}{$31 \infty$} & \multicolumn{2}{|c|}{ TOTALS } \\
\hline & $I^{1} I^{2}$ & I & II & & II & I & II & I I & II & I & II & I & II \\
\hline Recirculation & 1 & 1 & 3 & 2 & 3 & 1 & 2 & & 3 & 4 & 3 & 9 & 18 \\
\hline Prainback & 6 & & 1 & & 2 & & 1 & 1 & 1 & & & 2 & וו \\
\hline Closed Loop & 4 & & & 2 & 5 & & 1 & 1 & & 2 & & 5 & 10 \\
\hline Manual Freeze & & & & & & & & & & 1 & & 1 & \\
\hline Subtotals & 214 & 1 & 4 & 4 & 10 & 1 & 4 & 2 & 4 & 7 & 3 & 17 & 39 \\
\hline \# of Systems & 49 & 7 & & 7 & & 6 & & & 8 & 2 & & & \\
\hline $\begin{array}{l}\text { \# of Problems } \\
\text { Per System }\end{array}$ & .04 .29 & .01 & .05 & .05 & .13 & .01 & .06 & .07 & .14 & .27 & .12 & & \\
\hline Draindown & 3 & 2 & 6 & 3 & 3 & 1 & & & & & & 15 & 12 \\
\hline $\begin{array}{l}\text { \# Draindown } \\
\text { Systems }\end{array}$ & 12 & 1 & & 1 & 6 & 1 & & & 2 & & & & \\
\hline $\begin{array}{l}\text { \# of Problems } \\
\text { Per DD System }\end{array}$ & $.75 \quad .25$ & .13 & .38 & .19 & 19 & .08 & & & & & & & \\
\hline $\begin{array}{l}\text { Total \# of } \\
\text { Problems }\end{array}$ & 17 & 3 & 10 & 7 & 13 & 2 & 4 & 2 & 4 & 7 & 3 & 32 & 51 \\
\hline $\begin{array}{l}\text { * of Reporting } \\
\text { Systems }\end{array}$ & 61 & & & 9 & 3 & 8 & & & 30 & 2 & & & \\
\hline $\begin{array}{l}\text { Total \# of } \\
\text { Problems Per } \\
\text { System }\end{array}$ & $.18 \quad .28$ & .03 & 11 & .08 & .14 & .02 & .05 & .07 & .13 & .27 & .12 & & \\
\hline
\end{tabular}

NOTES: 1) See Note 1, Table 3

2) See Note 2, Table 3

TABLE 4. NUMBER OF PROBLEM AREAS FOR SYSTEM OPERATIONAL TIMES ACCORDING TO SYSTEM TYPE 
MONTHS OF OPERATION

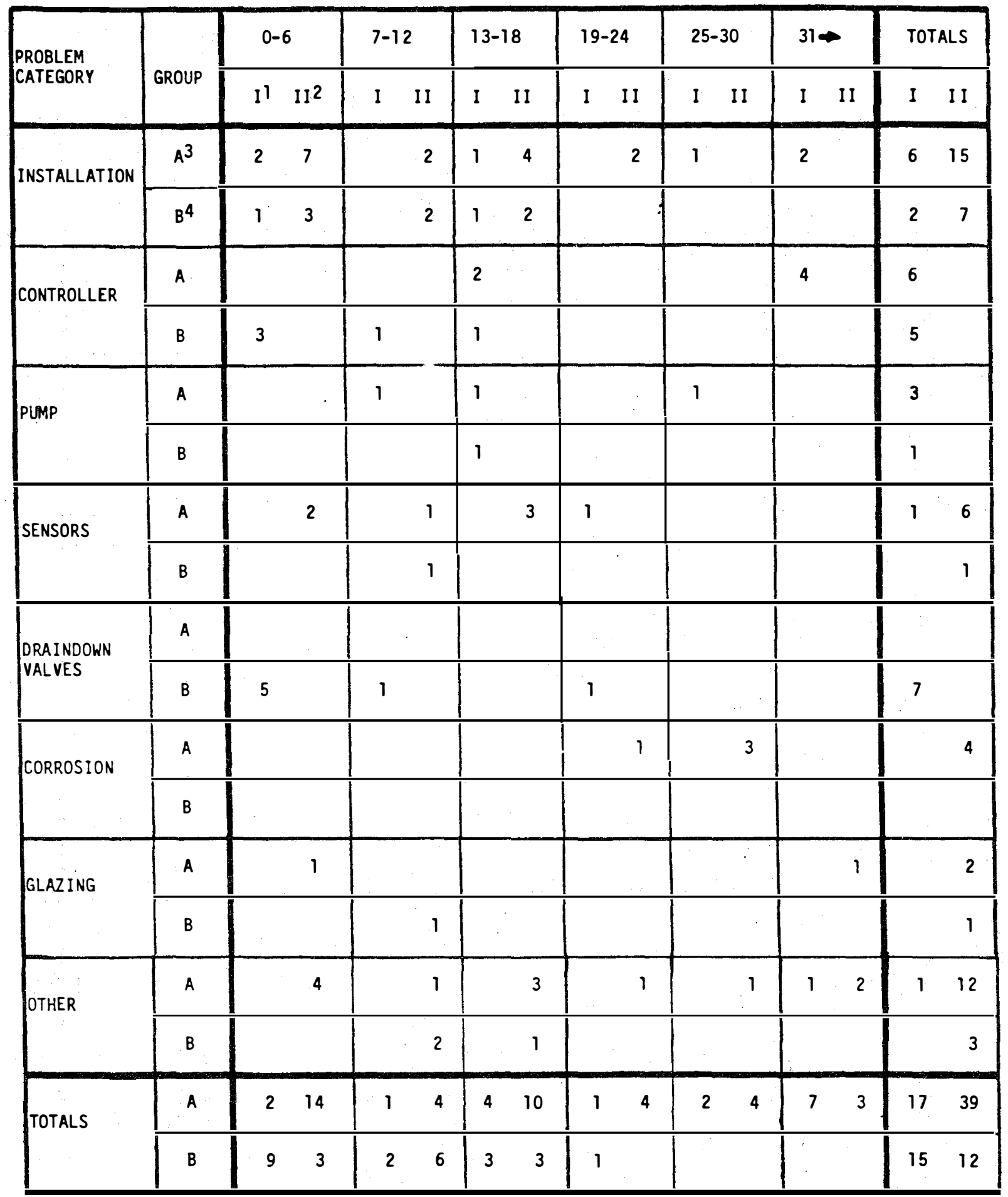

Notes: 1) See Note 1, Table 3.

2) See Note 2, Table 3.

3) Group A includes recirculation, drainback, closed 10op, and manual freeze system types.

4)Group B includes draindown systems only.

TABLE 5. NUMBER OF PROBLEM AREAS FOR SYSTEM OPERATIONAL

TIMES ACCORDING TO PROBLEM CATEGORIES 


\begin{tabular}{|c|c|c|c|c|c|}
\hline . & SPRING & SUMMER & FALL & WINTER & TOTALS \\
\hline & $I^{1} \quad I^{2}$ & I II & I II & I II & I II \\
\hline Recirculation & 24 & 14 & 25 & 45 & $9 \quad 18$ \\
\hline Draindown & -4 & 21 & 31 & 106 & $15 \quad 12$ \\
\hline Drainback & $-\quad-$ & 15 & -4 & 12 & 211 \\
\hline Closed Loop & 13 & 14 & 21 & 12 & $5 \quad 10$ \\
\hline Manual Freeze & $-\quad-$ & $-\quad-$ & - & 1 & 1 \\
\hline Totals & 311 & $5 \quad 14$ & 711 & $17 \quad 15$ & 3251 \\
\hline$\%$ of Totals & $9 \% 22 \%$ & $16 \% 27 \%$ & $22 \% 22 \%$ & $53 \% 29 \%$ & $-\quad-$ \\
\hline
\end{tabular}

Notes: 1)See Note 1, Table 3.

2) See Note 2, Table 3.

TABLE 6. SEASONAL VARIATIONS IN NUMBER OF PROBLEM AREAS ACCORDING TO SYSTEM TYPE 


\begin{tabular}{|l|cccc|c|}
\hline PROBLEM AREA & SPRING & SUMMER & FALL & WINTER & TOTALS \\
\hline Installation & $5(17 \%) *$ & $8(27 \%)$ & $7(23 \%)$ & $10(33 \%)$ & 30 \\
\hline Controller & $2(18 \%)$ & $2(18 \%)$ & $3(27 \%)$ & $4(36 \%)$ & 11 \\
\hline Pump & $1(25 \%)$ & $1(25 \%)$ & $1(25 \%)$ & $1(25 \%)$ & 4 \\
\hline Sensor & $3(38 \%)$ & $3(38 \%)$ & $1(13 \%)$ & $1(13 \%)$ & 8 \\
\hline Draindown Valves & $0(0 \%)$ & $0(0 \%)$ & $1(14 \%)$ & $6(86 \%)$ & 7 \\
\hline Corrosion & $0(0 \%)$ & $0(0 \%)$ & $2(50 \%)$ & $2(50 \%)$ & 4 \\
\hline Glazing & $14(17 \%)$ & $19(23 \%)$ & $18(22 \%)$ & $32(39 \%)$ & 83 \\
\hline Tother & $0(0 \%)$ & $0(0 \%)$ & $1(33 \%)$ & $2(67 \%)$ & 3 \\
\hline \hline
\end{tabular}

* - $\%$ of Total

TABLE 7. SEASONAL VARIATIONS IN NUMBER OF PROBLEM AREAS ACCORDING TO PROBLEM CATEGORY 


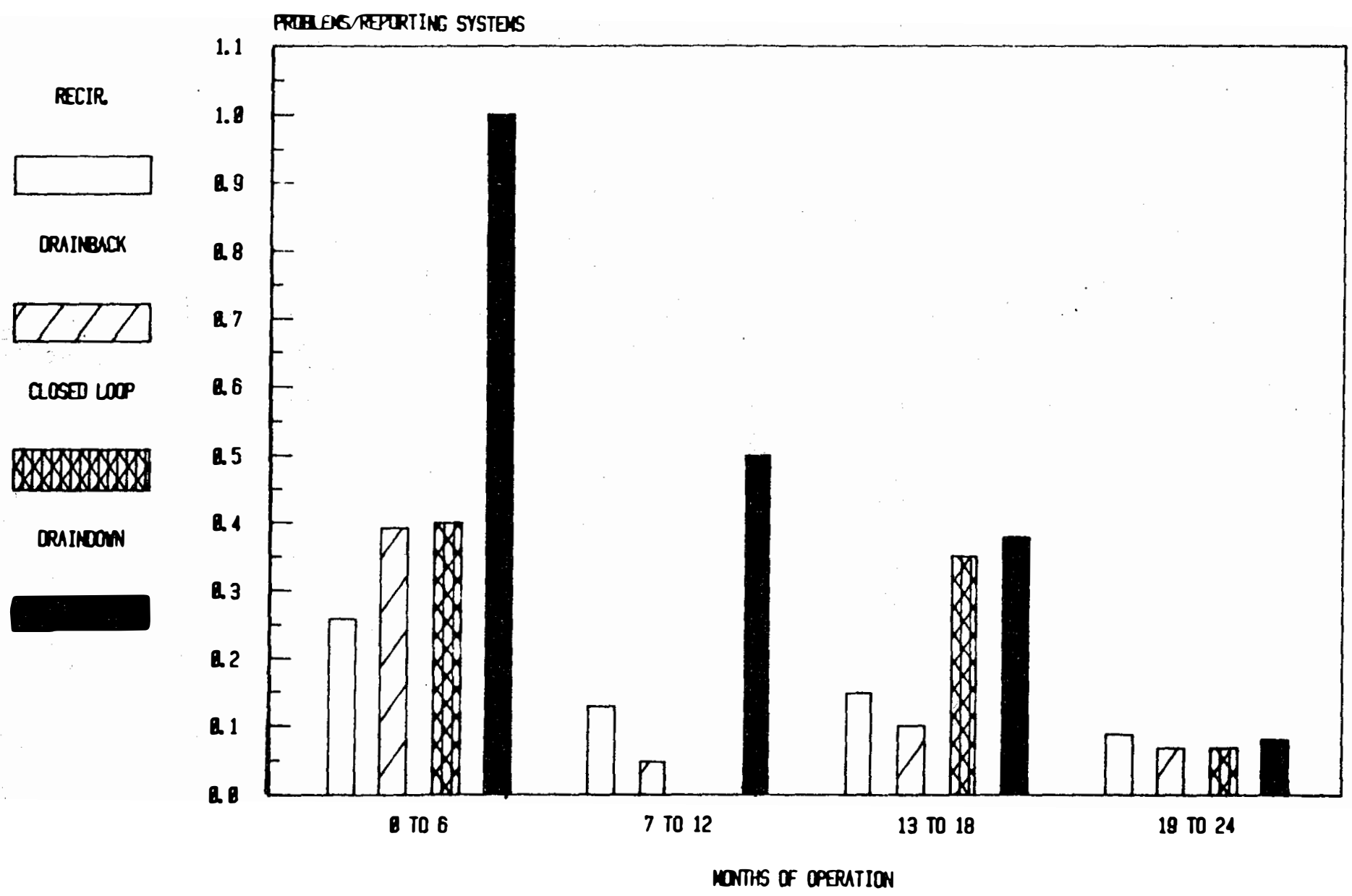

Notes: 1) See explanation in text concerning reduced number of working draindowil systems.

2 ) See discussion in text concerning number of problem areas after two years of operation, see also Table 5.

FIGURE 1. PROBLEMS PER REPORTING SYSTEMS FOR VARIOUS SYSTEM TYPES OVER TIME 


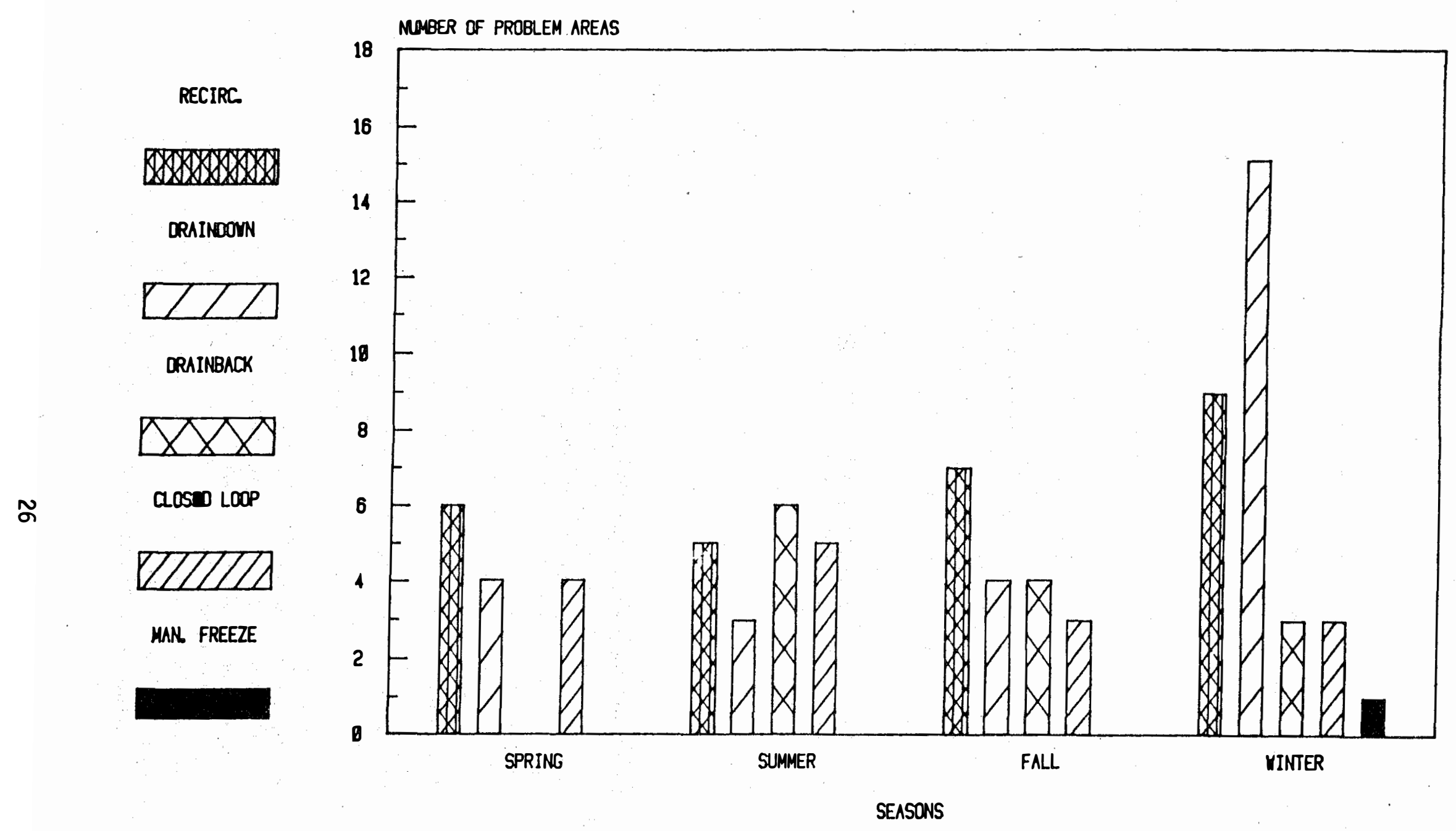

FIGURE 2. SEASONAL VARIATION IN NUMBER OF PROBLEM AREAS ACCORDING TO SYSTEM TYPE 
APPENDIX A

PROGRAM PARTICIPANTS SURVEY FORMS PACKAGE:

- Excerpt from Letter to All Homeowners

- Da ta Form A (Homeowner)

- Data Form B (Homeowner)

- Excerpt from Letter to All Installers

- Data Form A (Installer)

- Data Form B (Installer) 
Si te Code

Excerpt from Letter to All Homeowners:

We would like to now ask you and your family for an additional effort in providing us information concerning the reliability and user experiences you have had with your monitored system. At the same time, we will send a letter to your system installer for additional information on his solar systems being monitored under the program, including your system.

We would greatly appreciate your aid in completing two types of data forms which are enclosed. The "A" Data Form is directly concerned with the specific problem areas your system has experienced in the monitoring program. Our objective is to collect data on each of the problems which were encountered. This will be useful in guiding future research programs. I might hasten to add, we do see the overall performance of the monitored systems as quite good. Hopefully, your inputs will help make even better components available in the future.

A package of the "A" Data Forms is enclosed along with your latest Monthly Summary Report. We ask that you complete a separate "A" Data Form for each problem noted on the summary. We have noted with a red line each instance where there appeared to be a problem. Also, if you know of other problems which are not listed on the performance summary, please complete an additional questionnaire on each such problem. Fortunately, there are not too many of these events so your job should not be difficult. We do recognize that you will have to "search your memory" to provide full details. Please do the best you can to recall each event. If you think that I can help by explaining any of the coding on the performance sheet, please call. Enclosed with the "A" data form is a reference sheet entitled "Examples of System Problem Areas." Please review this sheet prior to completing the forms in order to familiarize yourself with the problem areas of concern.

After completion of your group of "A" Data Forms, please complete the "B" Data Form which provides general information concerning the impact of your system on your daily living patterns. We believe that your experience is extremely valuable for assessing the most important areas concerning field operation and system reliability. As you know, field experience is where this type of data can best be gathered. This form is self-explanatory and does not require any reference to the performance monitoring data. 
The additional data to be furnished by you and your family will only be utilized as part of the statistical data. Your answers will be identified by your site code number. The data gathered will only be summarized and will not be reported individually, or identified, in any way to anyone.

Let me know if you have any questions or comments concerning the program or this additional effort. Enclosed is a prepaid envelope for returning the completed forms. Your cooperation and assistance is greatly appreciated.

(Letter continues with closing statement and expression of thanks--signed by W. M. Jones, ESG Program Manager.)

\section{Enclosures:}

Data Form A

Data Form B 
Introduction

Refer to the Monthly Summary sheet on your monitored system which is provided separately. On this sheet, any identified problem is marked with a red line which usually keys to the date of the occurrence. Utilize the enclosed list entitled "Examples of System Problem Areas" as a reference.

Please complete a separate questionnaire for each problem using the date to differentiate between two or more problems of your system. If you know of a problem not identified on the Monthly Summary sheet, please identify it and use the approximate date.

Telephone ESG, Inc. at (404) 457-8790 if you have any questions. Ask for William M. Jones.

\section{Items as Fol lows:}

1. Homecwner Name

Location (City and State)

2. Site Code (from Monthly Summary Sheet)

3. Approximate Date of Problem

(from Summary Sheet or other sources)

4. Describe the problem with your system, i.e., what were the symptoms?

5. How did you know the problem existed?

6. Describe the corrective maintenance performed on-site.

7. Name any system components that were replaced. 
8. Indicate the cause of the system or component problem.

9. What was the cost to you for repair or replacement?

10. Was the repair or replacement cost covered under any warranty?

11. Did the initial failure cause other problems with this system?

If yes, please describe.

12. Additional comments (use extra sheet if necessary). 
The following is a list of areas where your system could have experienced problems. Please review this list prior to completing the data forms enclosed.

A. Controller:

- Pump not running at all

- Pump running at night or when sun not available

- Pump running at all times

- Improper calibration (reduced efficiency even though system may operate)

B. Sensors:

- Defective sensor

- Faulty wiring

C. Tanks:

- Improper sensor placement

- Leaking tank (solar or conventional)

- Corrosion or sediment buildup

- Electric element in tank burned out

D. Pump:

- Thermostat setting indicating wrong temperature

- Pump failure (collector loop or heat exchanger loop)

E. Collectors:

- Pump Cavitating (Airlock)

- Condensation on transparent cover

- Leaking pipe in collector

- Broken glass cover

- Faded glass or plastic cover

- Collector support structure problem

F. Piping:

- Leaking pipe on roof

- Leaking pipe in-house

- Piping material deteriorated (plastic pipe)

- Piping insulation degraded on roof (shrunk or fell off)

- Scale or corrosion buildup in pipes

G. Freeze Damage:

- Sagging pipes trapped water on roof (improper drainage)

- Controls failed causing freeze damage

- Draindown valve failure

- Antifreeze solution ineffective

H. Other System Elements:

- Heat exchanger corrosion or scale buildup

- Leaking heat exchanger

- Draindown valve failure

- Draindown valve leaking (seals)

- Vacuum breaker failure

- Air vent failure

- Tempering valve defective

- Pressure/temperature relief valve failure

- Shading problems

- Water leak at particular components or locations 
Homeowner Name

City

State

Si te code

Introduction

This is intended to draw on your experiences as a homeowner with an installed solar water heater in order to better understand how your system is performing and how you have been using the system. Please be as informative as possible in completing this form.

Section 1 - General System Information

1. Approximately when was your solar system installed?

2. Please indicate the storage tank thermostat setting and any seasonal changes you might make during the year.

- Tank Thermostat Settings All Year Winter Summer

Actual Tank Temperature $\left({ }^{\circ} \mathrm{F}\right)$ Setting

or

Hi-Medium-Low Setting

3. How does your solar system's tank thermostat setting compare to your previous conventional tank thermostat setting prior to your solar system installation? (Check one) lower; higher; the same.

4. Please check [ ] the appropriate item concerning how your backup electric element in your tank is operated.

Power to element on year round and never changed.

- Power to el ement is cortrolled seasonally. Power to element contrulled by timer. Power to element is controlled manually and turned on when, no hot water; before baths, clothes washing, dishwashing, etc., only every so often, no particular time other, explain

5. During the first year of operation for your residential solar hot water system, what was the number of follow-up service calls by the installer to your house?

6. Of these return visits by the installer, what is the number of times when you believed there was a problem, but the installer explained that there actually was no problem? 
1. Please check [ ] your typical time of day hot water use.

Morning Afternoon Evening $\begin{aligned} & \text { No Special } \\ & \text { Time of Day }\end{aligned}$

- Clothes Washing

- Di shwashing

- Shower/Baths

2. Do you believe you use the most hot water during the afternoon; evening. (Check one item)

3. Does your family do the major hot water usages, such as clothes washings, only on days when there was very good sunshine? (Yes or No)

4. Have you changed the time of day you use hot water as a result of your solar hot water system purchase? (Yes or No)

Explain briefly.

5. Are you glad you bought a solar water heater?

Please explain.

Section III - Additional Information

1. What is your house thermostat setting? (OF) winter; fall and spring.

summer;

2. In the last four years, has your family, (check where appropriate)

added storm windows added weatherstripping or recaulked windows and/or doors added insulation to house

3. Homeowner comments. 
Installer Code

Excerpt from Letter to All Installers:

We would like to now ask you and your company for an additional effort in providing us information concerning the reliability experience you have had in general and with the monitored systems in particular. At the same time, we will send a letter asking the individual homeowners for information on any impact the solar system has had on their daily living patterns or the way in which they have decided to use their systems to gain the most benefit for themselves. We will also attempt to obtain the homeowner's comments on overall system operation and any problems; however, we do not anticipate that the homeowner inputs will provide detailed information.

We would greatly appreciate your aid in completing two types of data forms which are enclosed. The " $A$ " Data Form is directly concerned with the systems which have been in the monitoring program. Our objective is to collect data on each of the problems which were encountered. This will be useful in guiding future research programs. I might hasten to add, we do see the overali performance of the monitored systems as quite good. Hopefully, your inputs will help make even better components available in the future.

A package of the "A" Data Forms is enclosed along with Monthly Summary sheets from your monitored systems. We ask that you compl te a separate "A" Data Form for each problem noted on the summaries. We have noted with a red line each instance where there appeared to be a problem. Also, if you know of other problems which are not listed on a performance summary, please complete an additional questionnaire on each such problem. Fortunately, there are not too many of these events so your job should not be difficult. We do recognize that you may have to refer to your own service records or otherwise "search your memory" to provide full details. Please do the best you can to recall each event. If you think that I can help by explaining any of the coding on the performance sheet, please call.

After completion of your group of "A" Data Forms, please complete the "B" Data Form which provides general information related to reliability problems in the field. We believe that your field experience with all of your installed equipment is extremely valuable for assessing the most important areas concerning maintenance and reliability. As you know, field experience is where system reliability characteristics can best be gathered. This form is self-explanatory and does not require any reference to the performance monitoring data. 
The additional data to be furnished by you and your company will only be utilized as part of the statistical data.

(Followed by closing comments and expression of appreciation for the firm's assistance--signed by William M. Jones, Program Manager.)

Enclosures:

Data Form A

Data Form B 
Introduction

Refer to the Monthly Summary sheets on your monitored sites which are provided separately. On these sheets, any identified problem is marked with a red line which usually keys to the date of the occurrence.

Please complete a separate questionnaire for each problem using the date to differentiate between two or more problems at one site. If you know of a problem not identified on the Monthly Summary sheet, please identify it and use the approximate date.

Telephone ESG, Inc. at (404) 457-8790 if you have any questions. Ask for William M. Jones.

Items as Follows:

1. Installer Name

Location (City and State)

2. Site Code (from Monthly Summary Sheets)

3. Approximate Date of Problem

(from Summary Sheet or other sources)

4. Describe the problem with this system, i.e., what were the symptoms?

5. How did the homeowner know the problem existed?

6. Describe the corrective maintenance performed on-site.

7. Name any system components that were replaced. 
8. Indicate the cause of the system or component problem.

9. What was the cost to the homeowner for repair or replacement?

10. Was the repair or replacement cost covered under any warranty?

11. Did the initial failure cause other problems with this system? If yes, please describe.

12. Additional comments (use extra sheet if necessary). 
DATA FORM B: GENERAL SYSTEM FIELD PERFORMANCE

Installer Name

Introduction

This is intended to utilize your field experience as a key installer ir your area to obtain an overview of the most important reliability anc maintainability areas experienced during the past two years. Please draw on your experience with all of your residential solar water heater installations to provide the rankings and other information requested below.

Section 1 Ranking and Identification of Problem Areas Most Frequently Encountered in the Field

Step 1: There are eight categories listed below which represent the areas where residential solar water heater problems occur. Carefully review these eight categories identified by the letters A through $H$. In the box provided next to each category, rank the categories with the numbers 1 to 8 with the rank of 1 as the most frequent problem area.

Step 2: After the eight categories are ranked, please review the items or characteristics listed within each category. Circle the two most frequent $i$ tems within each of the eight ranked categories.

A. Controller: (circle 2 of the following)

RANK

- Pump not running at all

- Pump running at night or when sun not available

- Pump running at all times

- Improper calibration (reduced efficiency even though system may operate)

- $\quad$ other

B. Sensors: (circle 2 of the following)

RANK

- Defective sensor

- Faulty wiring

- Improper sensor placement

- Other

C. Tanks: (circle 2 of the following)

RANK

- Leaking tank (solar or conventional)

- Corrosion or sediment buildup

- Electric element in tank burned out

- Thermostat setting indicating wrong temperature

- Other 
D. Pump: (circle 2 of the following)

RANK

RANK

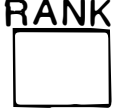

RANK

RANK
- Pump failure (collector loop or heat exchanger loop)

- Pump Cavitating (Airlock)

- Other

E. Collectors: (circle 2 of the following)

- Condensation on transparent cover

- Leaking pipe in collector

- Broken glass cover

- Faded glass or plastic cover

- Collector support structure problem

- Other

F. Piping: (circle 2 of the following)

- Leaking pipe on roof

- Leaking pipe in-house

- Piping material deteriorated (plastic pipe)

- Piping insulation degraded on roof (shrunk or fell off)

- Scale or corrosion buildup in pipes

- Other

G. Freeze Damage: (circle 2 of the following)

- Sagging pipes trapped water on roof (improper drainage)

- Controls failed causing freeze damage

- Draindown valve failure

- Antifreeze solution ineffective

- Other

H. Other System El ements: (circle 2 of the following)

- Heat exchanger corrosion or scale buildup

- Leaking heat exchanger

- Draindown valve failure

- Draindown valve leaking (seals)

- Vacuum breaker failure

- Air vent failure

- Tempering valve defective

- Pressure/temperature relief valve failure

- Shading problems

- Water leak at particular components or locations

- Other 
Section II General System Performance Information

Please complete the following:

1. Please indicate the appropriate percentages of the causes of system reliability problems encountered in the field with residential solar hot water systems.

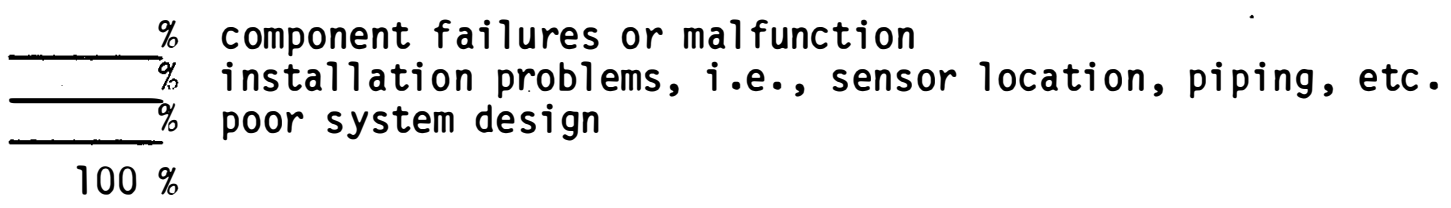

2. Please indicate the appropriate percentages when residential system reliability problems generally occur.

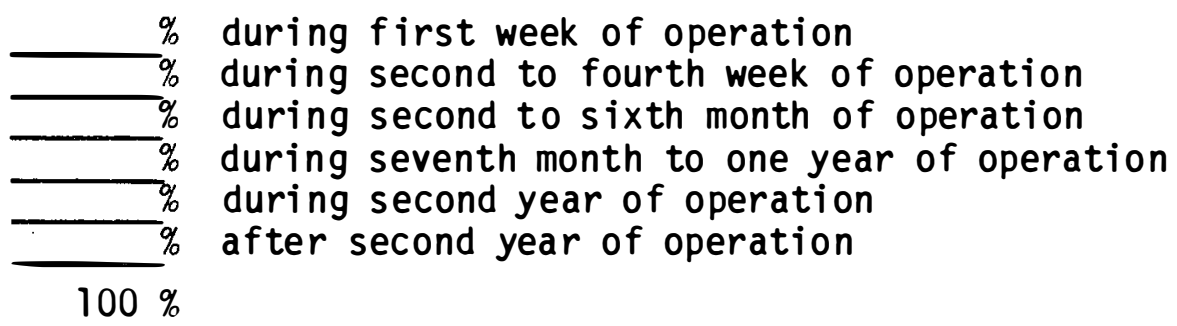

3. What are the major reasons the listed residential system components either failed or malfunctioned in the field?

- Pumps

- Controls

- Piping

- Tanks

- Other Major Components (i.e., Heat Exchangers, Draindown Valves, etc.) Please List 
4. During the first year of operation for a residential solar hot water system, what is the average number of follow-up service calls to that site?

5. Of these return visits, what is the number of times when the homeowner believed there was a problem, but there actually was no problem?

6. Installer Comments 
APPENDIX B

INSTALLER FIELD EXPERIENCES SURVEY RESULTS

As part of the installer survey forms package, a section was included to gather information on the overall field experience of the installers. ESG requested that each installer complete this section and base the answers on his company's experiences with residential solar water heaters over the past two years. ESG provided the installers with a list of eight system components and problem areas categories and requested that they rank the categories according to frequency of occurrence. The eight categories are listed in Appendix A on the Installer Data Form B.

As shown in Appendix $A$, each of the eight categories had a number of subcategories which characterized a prevalent problem area. The installers were requested to rank the problem or component category one through eight, with one being the most frequent. The two most frequent subcategories were to be circled by the installers. Table $B-1$ shows the average values for each ranked category. Also shown in Table $B-1$ are the two most frequent subcategories and the respective number of installers which identified this subcategory as most frequent.

There were a total of twelve installers who responded to this survey. Seven installers were located in Florida. The remaining five installers were located as follows: Virginia - 3; Georgia - 1; Alabama - 1. The majority of the responding installers have been in the solar industry for over five years and, of course, none fewer than 2.0 years in business.

As shown in Table $B-1$, the two system components most likely to have problems are controllers and sensors. Controllers are the most troublesome component. The two most frequent causes of controller malfunction is reportedly due to manufacturers' circuit board defects or power surges inflicted on the controller by nearby lightning strikes. 
The most reliable components of the systems are reported to be the collector and storage subsystems. The most frequent problem with the storage subsystem is identified as the electric element burning out. This is actually a non-solar problem area. The collector system is indicated as the least problem plagued system component. The installers reported that when a collector problem is realized it is usually condensation on the glazing or a faded plastic glazing cover.

The installers' overall field experiences concerning systems operational reliability and maintainability is closely aligned with the results from the R\&M survey of the field test systems. It is encouraging to note the similarity of results and amounts of verifiable data gathered. A comparison of results from both surveys indicates the following similarities:

1) The collector and storage subsystems are the two most reliable system components.

2) Controller and sensor malfunctions are two of the most frequent system R\&M problem areas.

3) Draindown valve failures are prevalent causes of system problems and freeze damage.

4) Nearby lightning strikes cause a significant number of controller failures.

As mentioned, twelve installers responded to the survey concerning an overview of their respective field experiences with residential solar water heaters. The following are four selected questions and results from the survey forms. The results are averaged values. 
1. Please indicate the appropriate percentage of the causes of system reliability problems encountered in the field with residential solar hot water systems.

$76 \%$ component failures or malfunctions

$22 \%$ installation problem i.e., sensor location, piping, etc.

$2 \%$ poor system design

2. Please indicate the appropriate percentages when residential system reliability problems generally occur.

$60 \%$ during first week of operation

$5 \%$ during second to fourth week of operation

$5 \%$ during second to sixth month of operation

$7 \%$ during seventh month to one year of operation

$8 \%$ during second year of operation

$16 \%$ after second year of operation

3. During the first year of operation for a residential solar hot water system, what is the average number of followup service calls to that site?

Answer:

0.9 site visits/year

4. Of these return visits, what is the number of times when the homeowner believed there was a problem, but there actually was no problem?

Answer:

$37 \%$ of the time

B-3 


\begin{tabular}{|c|c|c|c|}
\hline $\begin{array}{l}\text { PROBLEM } \\
\text { CATEGORY }\end{array}$ & $\begin{array}{l}\text { AVERAGE* } \\
\text { RANK }\end{array}$ & $\begin{array}{c}\text { SUBCATEGORY - two most } \\
\text { frequent events with in each } \\
\text { problem category }\end{array}$ & $\begin{array}{l}\text { \# of Installers } \\
\text { Concurring ( } 12 \\
\text { possible) }\end{array}$ \\
\hline Controllers & 2.5 & $\begin{array}{l}\text { - Pump running at night } \\
\text { - Pump running at ali times }\end{array}$ & $\begin{array}{l}6 \\
6\end{array}$ \\
\hline Sensors & 3.7 & $\begin{array}{l}\text { - Defective sensors } \\
\text { - Faulty wiring }\end{array}$ & $\begin{array}{l}9 \\
4\end{array}$ \\
\hline $\begin{array}{l}\text { Other System } \\
\text { El ements }\end{array}$ & 4.0 & $\begin{array}{l}\text { - P/T valve failure } \\
\text { - Air Vent failure }\end{array}$ & $\begin{array}{l}7 \\
4\end{array}$ \\
\hline Freeze Damage & 4.5 & $\begin{array}{l}\text { - Draindown valve failure } \\
\text { - Sagging pipes }\end{array}$ & $\begin{array}{l}4 \\
4\end{array}$ \\
\hline Pumps & 4.5 & $\begin{array}{l}\text { - Pump cavitating (airlock) } \\
\text { - Pump failure }\end{array}$ & $\begin{array}{l}7 \\
6\end{array}$ \\
\hline Piping & 4.9 & - Insulation degradation & 10 \\
\hline Tanks & 5.0 & $\begin{array}{l}\text { - Electric element failure } \\
\text { - Thermostat setting incorrect }\end{array}$ & $\begin{array}{l}8 \\
4\end{array}$ \\
\hline Collectors & 6.7 & $\begin{array}{l}\text { - Condensation on glass cover } \\
\text { - Faded glass or plastic cover }\end{array}$ & $\begin{array}{l}4 \\
4\end{array}$ \\
\hline
\end{tabular}

TABLE B-1. RESULTS FROM INSTALLER FIELD EXPERIENCE SURVEY 


\section{SELECTED DISTRIBUTION LIST}

John Avery

Los Alamos National Laboratory

MS K-573

P.0. Box 1663

Los Alamos, NM 87545

Donald Bowden

Solar Unlimited, Inc. No. 37 Traylor Island

Huntsville, AL 35801.

Kirk Collier, Ph.D.

Collier Engineering

Rt. 2, Box 240

Cave Creek, AZ 85331

James Collner, Director

Research and Engineering

American Solar King

P.0. Box 7399

Waco, TX 76710

Jonathan Ben Costa

Pacific Gas and Electric Co.

77 Beale Street

San Francisco, CA 94106

Brad Davis, Vice President

Nat'1. Assn. of Solar Contractors

Marc Engineering Corporation

2712 Burgandy Drive

Cinnaminson, NJ 08077

Mr. Robert A. Diehl

Energy Services

Baltimore Gas and Electric

P.0. Box 1475

Baltimore, MD 21203

Robert D. Dikkers

National Bureau of Standards

Technology B-148

Washington, DC 20234

Webb Farber

U.S. Solar Corporation

P.0. Drawer K

Hampton, FL 32044
Joe Frissora

Sunmaster Corp.

35 W. William Street

Corning, NY 14830

Ed Gray

JRB Associates

8400 W. Park Drive

McLean, VA 22102

Sally Hooks

Marketing Department

Long Island Lighting Company

250 0ld Country Road

Mineola, NY 11501

Peter Jacobs

Novan Energy, Inc.

1630 N. 63rd St.

Boulder, CO 80301

William M. Jones

Energy Systems Group

$E S G$, Inc.

2231 Perimeter Park, Suite 11

Atlanta, GA 30341

Susumu Karaki,

Solar Applications Laboratory

Solar House No. 2

Colorado State University

Ft. Collins, CO 80523

Paul W. Kendall

Vitro Laboratories

14000 Georgia Avenue

Silver Spring, MD 20910

William J. Kennish

Vice President

TPI, Inc.

5010 Sunnyside Avenue, Suite 301

Beltsville, MD 20705

John Long

Tennessee Valley Authority

400 Commerce Avenue, SW

Knoxville, TN 37902 
Pamela S. McKeever

Public Service Co. of N. Mex. Alvarado Square

Albuquerque, NM 87158

Jack Meeker

8 Gerrity Street

Wilmington, MA 01887

Stan Moore

Los Alamos National Laboratory

MS K-571

P.0. Box 1663

Los Alamos, NM 87545

David S. Odegard

Northern Energy Corporation

470 Atlanta Avenue

Boston, MA 02210

Andrew J. Parker

Executive Vice President

Mueller Associates, Inc.

1900 Sulphur Spring Road

Baltimore, MD 21227

Paul J. Pekrul

Rockwell ETEC

P.0. Box 1449

Canoga Park, CA 91304

Gary Purcell

Electric Power Research Institute

3412 Hillview Avenue

Palo Alto, CA 94303

Richard Rittlemann

Burt, Hill, Kosar, Rittleman Associates

400 Morgan Center

Butler, PA 16001

Sherry Rossi

Vitro Laboratories

14000 Georgia Avenue

Silver Spring, MD 20910
William W. Schertz

Argonne National Laboratory

9700 South Cass Avenue

Argonne, IL 60439

Richard Silberglitt, Ph.D.

DHR, Inc.

6858 01d Dominion Drive

McLean, VA 22101

Robert Spears

Development Project Director

Reynolds Products and Process

Development Laboratory

P.0. Box 27003

Richmond, VA 23261

Bill Stoney

RCA Astro Electronics

P.0. Box 800

Princton, NJ 08540

Burt Swerdling

Project Engineer

Grumman Energy Systems, Inc.

445 Broadhollow Road

Melville, NY 17747

Byron Winn, Ph.D.

Mechanical Engineering Department

Colorado State University

Ft. Collins, CO 80523

Marvin Yarosh

Florida Solar Energy Center

300 State Road 401

Cape Canaveral, FL 32920

Solar Energy Research Institute

Craig Christensen

Robert Farrington

Lawrence Flowers

Ronald Judkoff

Allan Lewandowski

Lawrence M. Murphy

Walter Short 


\begin{tabular}{|c|c|c|c|}
\hline $\begin{array}{c}\text { Document Control } \\
\text { Page }\end{array}$ & $\begin{array}{l}\text { 1. SERI Report No. } \\
\text { SERI/STR-253-2531 }\end{array}$ & 2. NTIS Accession No. & 3. Recipient's Accession No. \\
\hline \multirow{2}{*}{\multicolumn{3}{|c|}{$\begin{array}{l}\text { 4. Title and Subtitle } \\
\text { Survey of System Operational Failure Modes from } 122 \\
\text { Residential Solar Water Heater Systems Over a Period } \\
\text { of Approximately Two Years }\end{array}$}} & $\begin{array}{r}\text { 5. Publication Date } \\
\text { October } 1984\end{array}$ \\
\hline & & & $\overline{6 .}$ \\
\hline \multicolumn{3}{|c|}{$\begin{array}{l}\text { 7. Author(s) } \\
\text { Charles Kutscher }\end{array}$} & 8. Performing Organization Rept. No. \\
\hline \multicolumn{3}{|c|}{ 9. Performing Organization Name and Address } & $\begin{array}{l}\text { 10. Project/Task/Work Unit No. } \\
7526.10\end{array}$ \\
\hline \multicolumn{3}{|c|}{$\begin{array}{l}\text { ESG, Inc. } \\
\text { Atlanta, Georgia }\end{array}$} & $\begin{array}{l}\text { 11. Contract (C) or Grant (G) No. } \\
\text { (C) HK-3-03128-1 } \\
\text { (G) }\end{array}$ \\
\hline \multicolumn{3}{|c|}{ 12. Sponsoring Organization Name and Address } & 13. Type of Report \& Period Covered \\
\hline \multirow{2}{*}{\multicolumn{3}{|c|}{$\begin{array}{l}\text { Solar Energy Research Institute } \\
1617 \text { Cole Boulevard } \\
\text { Golden, Colorado } 80401\end{array}$}} & Technical Report \\
\hline & & & 14. \\
\hline \multicolumn{4}{|l|}{ 15. Supplementary Notes } \\
\hline \multicolumn{4}{|c|}{$\begin{array}{l}\text { 16. Abstract (Limit: } 200 \text { words) } \\
\text { This report describes the results of a survey on the operation of active solar } \\
\text { heating and cooling systems and their components. Questionaires were sent to } \\
\text { homeowners and installers, covering } 122 \text { systems. Results were categorized } \\
\text { according to problem severity, location, system type, length of system operation, } \\
\text { and time of the year. Approximately } 47 \% \text { of the systems had at least one } \\
\text { reliability problem over a two-year period. Flat-plate collector and storage } \\
\text { systems were highly reliable. Improper operation of these components was } \\
\text { attributed to installation problems. Drainback designs also had the greatest } \\
\text { reliability; draindown systems were the least reliable, largely because of the } \\
\text { failure of draindown valves. Differential controllers caused the largest number } \\
\text { of failures that resulted in a repair cost in excess of } \$ 50 \text { to the homeowner. }\end{array}$} \\
\hline
\end{tabular}

17. Document Analysis

a. Descriptors Efficiency; Failures; Performance; Reliability; Residential Sector; Solar Water Heaters; Solar Water Heating; Surveys

b. Identifiers/Open-Ended Terms

c. UC Categories

$59 a$

18. Availability Statement

National Technical Information Service

U.S. Department of Commerce

5285 Port Royal Road

Springfield, Virginia 22161

19. No. of Pages

56 .

20. Price 